\title{
Sensitivity of a hydraulic model to changes in channel erosion during extreme flooding
}

Article

Accepted Version

Wong, J. S., Freer, J. E., Bates, P. D. and Stephens, E. M. (2014) Sensitivity of a hydraulic model to changes in channel erosion during extreme flooding. Hydrological Processes, 29 (2). pp. 261-279. ISSN 0885-6087 doi:

https://doi.org/10.1002/hyp.10148 Available at https://centaur.reading.ac.uk/37824/

It is advisable to refer to the publisher's version if you intend to cite from the work. See Guidance on citing.

To link to this article DOI: http://dx.doi.org/10.1002/hyp.10148

Publisher: Wiley InterScience

All outputs in CentAUR are protected by Intellectual Property Rights law, including copyright law. Copyright and IPR is retained by the creators or other copyright holders. Terms and conditions for use of this material are defined in the End User Agreement.

www.reading.ac.uk/centaur 
Central Archive at the University of Reading

Reading's research outputs online 
Page 1 of 19

\title{
Sensitivity analysis of a hydraulic model to changes in channel erosion during extreme flooding
}

\author{
Jefferson S. Wong ${ }^{\mathrm{a}}$, Jim E. Freer ${ }^{\mathrm{a}}$, Paul D. Bates ${ }^{\mathrm{a}}$, David A. Sear ${ }^{\mathrm{b}}$ and Elisabeth M. Stephens ${ }^{\mathrm{a}^{*}}$ \\ ${ }^{a}$ School of Geographical Sciences, University of Bristol, Bristol, UK \\ ${ }^{\mathrm{b}}$ School of Geography, University of Southampton, Southampton, UK \\ $\mathrm{a}^{*}$ Department of Geography and Environmental Science, University of Reading, Reading, UK
}

(1)

\section{Abstract}

Recent research into flood modelling has primarily concentrated on the simulation of inundation flow without considering the influences of channel morphology. River channels are often represented by a simplified geometry that is implicitly assumed to remain unchanged during flood simulations. However, field evidence demonstrates that significant morphological changes can occur during floods to mobilise the boundary sediments. Despite this, the effect of channel morphology on model results has been largely unexplored. To address this issue, the impact of channel cross-section geometry and channel long-profile variability on flood dynamics is examined using an ensemble of a 1D-2D hydraulic model (LISFLOOD-FP) of the 1:2102 year recurrence interval floods in Cockermouth, UK, within an uncertainty framework. A series of hypothetical scenarios of channel morphology were constructed based on a simple velocity based model of critical entrainment. A Monte-Carlo simulation framework was used to quantify the effects of channel morphology together with variations in the channel and floodplain roughness coefficients, grain size characteristics, and critical shear stress on measures of flood inundation. The results showed that the bed elevation modifications generated by the simplistic equations reflected a good approximation of the observed patterns of spatial erosion despite its overestimation of erosion depths. The effect of uncertainty on channel long-profile variability only affected the local flood dynamics and did not significantly affect the friction sensitivity and flood inundation mapping. The results imply that hydraulic models generally do not need to account for within event morphodynamic changes of the type and magnitude modelled, as these have a negligible impact that is smaller than other uncertainties, e.g. boundary conditions. Instead morphodynamic change needs to happen over a series of events to become large enough to change the hydrodynamics of floods in supply limited gravel-bed rivers like the one used in this research. 


\section{Introduction}

2 River morphology is both a control and consequence of fluvial processes (Sear et al., 2010). River channels subjected to morphological changes during a subset of flood events could have significant implications for floodplain inundation, flow depth, and floodwave propagation and the associated uncertainties. Numerous studies have addressed one or some of the types of the uncertainty in the modelling: model structural choice (e.g. Apel et al., 2009), model friction and conveyance parameters (e.g. Aronica et al., 1998; Romanowicz and Beven, 2003; Bates et al., 2004; Werner et al., 2005; Pappenberger et al., 2007), and boundary conditions (e.g. Pappenberger et al., 2006; Pappenberger et al., 2007). The sensitivity of flood inundation predictions to uncertainty of the geometry of the floodplain (e.g. Werner et al., 2005) and channel (e.g. Pappenberger et al., 2006; Pappenberger et al., 2007) (including the representation of natural and man-made flow control structures such as vegetation and buildings (e.g. Beven et al., 2012)) have also been evaluated. In addition, others have presented methodology for the estimation of uncertainty of the models, which takes account of the uncertainty in the observed data (e.g. Pappenberger et al., 2007; Di Baldassarre et al., 2009; Stephens et al., 2012; Stephens and Bates, In revision). Increased flooding is shown to be caused by either hydrologic changes that increase peak flows or geomorphic changes that reduce channel conveyance (Stover and Montgomery, 2001). Thus, how flood dynamics interact with morphological change is a topic of growing interest for hydraulic modelling (Fewtrell et al., 2011). Driving this motivation has been the basic question that, given the uncertainty inherent in other sources like observation error and boundary conditions, is it important to account for uncertainty in morphodynamic changes within a flood event? The standard hydraulic models adopted for risk mapping use a static representation of channel geometry, but without studies that quantify the uncertainties associated with a changing channel geometry it is impossible to know whether this is a significant uncertainty that is missing from the quantification of risk. This paper therefore addresses this question by assessing the impact of changes in channel long-profile and cross-section during an extreme flood event on water surface elevation and subsequently the depth and extent of flood inundation.

Reviewing the development in the flood risk estimation and flood inundation mapping literature finds that most of the numerical hydraulic models (e.g. Galland et al., 1991; Bates and De Roo, 2000; Brunner, 2002) are concentrated merely on the simulation of inundation flow without considering the influences of channel morphology and sediment delivery from upstream. In most cases hydrodynamic unsteady models are applied in which the river channels are considered as a means of access for flow conveyance rather than a device for controlling river flow patterns (Neuhold et al., 2009). It has been suggested that the complexity of channel geometry is not significant during large flood events as the whole floodplain and river channel can act as a single channel unit (Bates et al., 2005). River channels can then be represented by a simplified geometry that is implicitly assumed to remain unchanged during flood events and under long-term erosion and deposition. However, bedload may become highly mobile during floods, forces on the bed, banks and floodplain are sufficient to mobilise the boundary sediments resulting in significant changes in channel morphology (cross-section and long-profile) and even channel pattern (Kleinhans et al., 2013), resulting in modification of form roughness (Hey, 1979). This suggests that the influence of sediment and 
subsequent changes in bed elevation may be an important control on hydraulic and flood inundation modelling.

Following recent large flood events, during which significant and damaging morphological change occurred, both in the UK and other parts of the world (e.g. River Derwent in UK 2009, 2012; River Indus in Pakistan 2010), there is an increasing need to evaluate the impact and uncertainties introduced by morphological change on the accuracy of flood inundation modelling. Hydraulic models are not only sensitive to model parameters and the representation of hydraulic structures, but also the geometric description (Merwade et al., 2008). Fewtrell et al. (2011), for instance, showed that cross-section variability is less important than the channel long-profile in the calibration process with the use of a coupled dynamic 1D-2D hydraulic model (ESTRY-TUFLOW) of the Carlisle floods of January 2005. Other studies have addressed the intricacy of channel geometry representation and showed the flood inundation area will be influenced by the number and location of cross-sections (e.g. Cook and Merwade, 2009). Implementation of hydraulic models also requires the specification of suitable roughness parameters. Channel and floodplain roughness used in many studies (e.g. Aronica et al., 2002) are commonly examined in a calibration process based on observed flood inundation extent and flow depth. Roughness values, and the way in which they change with depth, are needed to compensate for the restrictions in the model representation of channel geometry, floodplain topography and energy dissipation at the scale of model resolution as such these roughness values are often referred to as 'effective' (e.g. Pappenberger et al., 2005; Werner et al., 2005). Therefore, reach scale effective values of roughness are required, but little attention is paid to the impact of geometric description on model sensitivity to roughness parameter values which can be highly uncertain.

Knowing the effect of uncertainty in channel geometry on roughness parameter values is not sufficient and the challenge is to, perhaps more importantly, assess the effect that such uncertainty may have on model performance. Channel geometry and floodplain topography are the principal variables that affect the flood wave propagation and are therefore critical to the prediction of flood dynamics. A small degree of uncertainty in bed elevation may have a relatively large effect on model predictions (Wilson and Atkinson, 2005). In a study of a 5.6km reach of the Upper River Wharfe, UK, Raven et al. (2009) showed that a mean bed level rise of $0.17 \mathrm{~m}$ over the six-year monitoring period had a significant effect on increasing the flood frequency by 2.6 times on average, and overbank flow time by 12.8 hours. Similarly, Stover and Montgomery (2001) concluded that whilst the requisite discharge for overbank flow and peak discharge had reduced, the frequency of flooding had increased as a result of aggradation on the mainstem Skokomish River, Washington State, USA. Furthermore, recent research that incorporates the implications of sediment delivery and river bed level changes on flood risk (Lane et al., 2007; Lane et al., 2008; Neuhold et al., 2009), have highlighted the fact that an effective flood inundation modelling strategy should be built on how sensitive the flood dynamics are to the changes not only in hydrological but also morphological processes.

In the light of current interest and recent research, the objectives of this paper are therefore 1) to develop an approach that reconstructs realistic changes (in terms of spatial patterns) in channel erosion during flood events; 2) to examine the impact of modelled bed elevation changes during a flood event on model sensitivity to roughness parameter values; 3) to assess the significance of 
modelled bed elevation changes on the prediction of flood depths; and, 4) to explore and quantify the differences arising from cross-section geometry and long-profile variability on flood inundation mapping. The recent extreme flooding in Cockermouth, UK provides a useful test because of the availability of high quality hydrological, flood inundation and morphological data for before and after flood conditions.

\section{Test Site and Data Availability}

The town of Cockermouth in North West Cumbria, UK, is situated at the confluence of one major river (River Derwent) and the River Cocker, with the River Marron joining the main River Derwent further downstream (Figure 1). This study reach, $32.27 \mathrm{~km}$ in length, was selected because: a) an extreme flood event in November 2009 caused significant morphological changes to the river channels and floodplain and, b) a data-rich case study that has multiple datasets of the observed flood extent at different times during the flood for evaluation of model performance was available.

The November 2009 event followed a prolonged period of rainfall over the catchment. A rain gauge at Seathwaite Farm in Borrowdale, about $24.1 \mathrm{~km}$ southeast of Cockermouth, recorded the highest $24 \mathrm{hr}$ total ever recorded in the UK of $316.4 \mathrm{~mm}$. Furthermore, major lakes and reservoirs within the region were already full and with the waterlogged upland catchment soil conditions, this resulted in a large amount of runoff into the river network. The resulting peak flow at Camerton gauging station on the Derwent was estimated by the Environment Agency of England and Wales (hereafter the EA) as $700 \mathrm{~m}^{3} \mathrm{~s}^{-1}$ and historic flood marks indicated that it was the largest event since at least 1899. The flood event was estimated to have a return period of 2102 years, with 95\% confidence limits of 507 and 17706 years (Miller et al., 2013). These high river flows destroyed six bridges and flooded 855 properties in Cockermouth and Workington. Sediment transport processes resulted in the largest changes in channel width since at least 1867, the date of the first accurate surveys of the river planform. Bank erosion, including the collapse of river cliffs up to $30 \mathrm{~m}$ in height, injected substantial quantities of sediment into the flooded river. Much of that material was then deposited on the floodplain and infilled pools within the river channels. In one area, the channel avulsed across the floodplain to create a new planform for the water flow.

The EA provided a digital elevation model (DEM) at $2 \mathrm{~m}$ resolution of the study site, generated from an airborne laser altimetry (LiDAR) survey flown in 1998 and April/May 2009. The majority of the data was from 1998 and had a vertical Root Mean Square Error (RMSE) of approximately 0.25m . Three different datasets of the observed flood extent were taken at different times during the flood: 1) aerial photography of the flood, which had a horizontal resolution of $0.15 \mathrm{~m}$, taken between $13: 10$ and 14:50 on $20^{\text {th }}$ November; 2) well defined wrack marks, which were visible along much of the extent of the flood in the aerial photograph and represent the maximum flood extent; and, 3) TERRASAR-X imagery, which had a $1 \mathrm{~m}$ horizontal resolution, captured at 18:02 on $21^{\text {st }}$ November. Water level measurements at 15 -min intervals were provided for three gauges around Cockermouth: upstream on River Derwent at Ouse Bridge and downstream at Camerton, and upstream on the River Cocker at Southwaite Bridge (See Figures $1 \& 2$ ). The Ouse Bridge gauge was bypassed during the flood. Yet, the EA had provided metadata to advise that the stage at the peak of the flood has been edited using estimates of the maximum flood level from a wrack survey, with the time of peak and the infilled data estimated using correlation techniques. The Camerton gauge was severely damaged 
during the flood event, the dataset with 'Good' readings only recorded up to 19th November 2009 at 20:30. After this, the only available data are through correlation with the Southwaite gauge. Flow data for the River Marron was provided by rescaling the flows in the Cocker using the comparative size of the catchments. Data to quantify the river channel geometry and bed material grain size of the River Derwent were also available. Some 234 and 191 channel cross-sections were surveyed for the study reach of the River Derwent in 1998 and 2010 respectively. The 1998 dataset were provided by the EA and was based on a composite of ISIS Section 105 model total station cross-section surveys, and repeat cross-sections within the town of Cockermouth. The 2010 data was based on crosssections surveyed by the EA in December 2009 from Workington to immediately upstream of Cockermouth. In addition, 127 repeat cross-sections were surveyed for the whole river in May and August 2010 by this study (See Table 1 for summary). The 2010 cross-sections were taken at locations close to those made in 1998, of which 93 could be paired as they were within 10m of each other.

As there were five major flood events between 2003 and 2008 (Figure 3) the 1998 DEM was updated and modified to provide a better representation of topography before the 2009 flood event. The 1998 DEM was built from a combination of datasets: 1998 LiDAR 2m DEM, 1998 cross-section survey, 2005 repeat cross-section survey for the reach through the town of Cockermouth, and bank outlines derived from the latest aerial photographs (1:3000) taken in 2004. <5\% of the total cross-sections, where bank migration had occurred between 1998 and 2004, were linearly interpolated out to the position of the 2004 bankline. In the area of wetted channel, 1998 (adjusted to 2004 banklines) and post-2005 flood cross-sections were interpolated to generate cross-sections at $5 \mathrm{~m}$ spacing throughout the whole channel using the method of Merwade et al. (2008) and Cook and Merwade (2009), with a RMSE of $0.235 \mathrm{~m}$. Using the 2004 banklines as 3D breaklines (Wheaton et al., 2010), the crosssection nodes were combined with the LiDAR 2m DEM data within the 2004 bankline mask to create a $2 \mathrm{~m}$ DEM for the wetted and non-wetted valley floor. Comparison of cross-sections surveyed post the 2005 flood in the reach through Cockermouth with those taken in 1998 show minor changes in bed elevation associated with submerged bars $(0.15+/-0.08 \mathrm{~m})$ and localised changes in bank outline. Therefore, the modified DEM was assumed to closely reflect the river morphology and topographic conditions at the time of the 2009 flood event.

\section{Methodology}

\subsection{Model setup}

The LISFLOOD-FP model was considered appropriate and was used in this paper for three reasons. Firstly, the model was relatively straightforward to implement (in terms of data requirement) and edit (in terms of changing river geometry). Secondly, the model code has been extensively validated and benchmarked, and is routinely employed in industrial applications (Hunter et al., 2008). Lastly, the model was not limited by computational burden given the large number of simulations required to fully examine the model sensitivities.

A 1D-2D LISFLOOD-FP model was then set up with the river channel represented by a diffusive wave solver as described by Trigg et al. (2009) and the floodplain represented by the inertial formulation of the shallow water equations as described by Bates et al. (2010). The location and structure of the channel in the channel component is specified as a series of XY coordinates that can 
be matched to a corresponding cell in the floodplain component and is represented using variables for channel width and bed elevation at each XY coordinate. In the model, water is routed through the channel component until flows exceed the channel capacity, at which point the excess flow divided between the two grid cells adjacent to the channel cell and entered the floodplain component.

The floodplain topography in the model was described using the modified DEM, rescaled to $20 \mathrm{~m}$ resolution to enable multiple simulations to be run for computational efficiency. The 1D channel model was driven by the 234 channel cross-section points extracted from the mid-points of each 1998 surveyed cross-section (Figure 4). The channel geometry was assumed to be a rectangular shape due to the inability of LISFLOOD-FP to represent complex irregular channels. The channel slopes were taken from the survey by allowing the channel bed to slope both positively and negatively. The channel widths were extracted by measuring the distance between two end points of each cross-section and the bed elevations of the channel were adjusted such that bank-full crosssectional flow area matched the surveyed bank-full flow area along the reach.

Instead of using the gauged data for Camerton as a downstream stage-varying boundary condition on account of the failure of the gauge during the event, a free boundary condition has been imposed. The River Derwent catchment is characterised as a gravel-bedded river $\left(\mathrm{D}_{50} 0.058 \pm 0.017 \mathrm{~m}\right)$ with pastural (grazed grass) land use dominating the floodplain across the catchment. According to Chow (1959) pasture with short grass would have a minimum Manning's $n$ of 0.025 , and a gravel bed would have a minimum of 0.030 . Some areas of the catchment are heavily forested or have medium to dense brush, which might expect a maximum Manning's $n$ value of 0.120 (Chow, 1959). To ensure that the entire range of potential friction values were sampled, and also accepting that friction as specified in LISFLOOD-FP acts as an effective value to parameterise un-modelled process and features such as sub-grid scale topography and three dimensional flow structures, a range of channel $\left(n_{c h}\right)$ and floodplain $\left(n_{f p}\right)$ friction values of between 0.020 and 0.140 were explored.

\subsection{Evaluation of model performance}

The two observed datasets (wrack marks and aerial photography) were processed by Stephens and Bates (In revision) to provide a total of 177 maximum water elevations and 3724 observed data points for model assessment. The outline of the flood in the TERRASAR-X image was also manually digitised and converted to 3353 data points from which known erroneous points, such as in vegetated areas, were removed.

Based on the analysis procedure described in Aronica et al. (2002), Monte-Carlo simulation using the GLUE technique (Beven and Binley, 1992) was adopted. 300 parameter sets were randomly sampled from the parameter space to evaluate model performance at the time steps when the observed datasets were collected. Mason et al. (2009) described two water surface elevation comparison methods (RMSE and paired $t$ test) to assess the acceptability of parameter sets. The use of paired $t$ test might be problematic as mentioned in Stephens et al. (2012) and therefore the RMSE will only be used in this study. The equation is defined as the square root of the mean square error and is given as

$R M S E=\sqrt{E\left(\left(\operatorname{sim}_{i}-o b s_{i}\right)^{2}\right)}$ 
where $i$ is the number of data points, sim the simulated nearest water surface elevation in the model, and $o b s$ the observed flood margin on DEM elevation.

According to their RMSE performances, the parameter sets were ranked and normalised into generalised likelihoods (Wagener et al., 2002). This measure could only be treated as analogous to a true probability as it could not be used for formal statistical inference (Wagener et al., 2002). Because of the unavoidably subjective process when no consistent error structure could be assumed (Freer et al., 2003), the top $20 \%$ of parameter sets were used to classify as behavioural simulations, the rest were rejected and their likelihoods were set to zero. Each parameter set was then weighted and assigned a value corresponding to how well the simulations reproduced the result in a global sense. The observed datasets were combined by evaluating on one dataset, then using another to update the weights assigned to each parameter set with the use of a recursive form of Bayes' equation (Lamb et al., 1998). The combined likelihood values associated with behavioural parameter sets were used to calculate and then map the relative probability $\left(P_{i}^{\text {flood }}\right)$ that a given pixel is inundated, using the following equation

$P_{i}^{\text {flood }}=\frac{\sum_{j} f_{i} W_{j}}{\sum_{j} W_{j}}$

where $j$ is the number of model simulations, $f_{i}$ represents the numerical model result at a pixel $i$ for each parameter set, and takes a value of 1 for a flooded pixel and is 0 otherwise. $W_{j}$ acts as a generalised relative measure for each simulation.

\subsection{Generation of bed elevation scenarios}

A simplified method was adopted to statically adjust the channel geometry at the beginning of the simulation due to the inability of LISFLOOD-FP to represent any morphodynamic processes and complicated technical demand to incorporate all processes (e.g. erosion, deposition, bank failure, etc.). Erosion during the flood peak was chosen as the focus of this paper because this is the point of the flood where flood extent and depths are greatest, and therefore has the highest risk as well as potential for geomorphological change. It is also the period when the largest sensitivities and uncertainties were most likely to be found. In addition, the majority of channel change was erosional, with deposition occurring as extensive gravel and sand sheets, on floodplains immediately downstream of river cliff failures. Lateral erosion (bank failure) was excluded in the erosion process to further reduce the complexity of parameter uncertainties. Therefore, changes in bed elevations at each cross-section were used as a simplified representation of changes in river morphology during the flood event.

The construction of hypothetical bed elevation scenarios was derived from a simplified duBoys-type sediment transport formulae (DuBoys, 1879) that have a shear stress relationship, which was developed by relating sediment transport to the threshold of incipient motion of sediments. For a fluid to begin transporting sediment that is currently at rest on a surface, the bed shear stress $\tau_{b}$ exerted by the fluid must exceed the critical shear stress $\tau_{c r}$ for the initiation motion of grains at the bed (Buffington and Montgomery, 1997). The bed shear stress $\tau_{b}$ is expressed as a force per unit area of the bed $\left(\mathrm{Nm}^{-2}\right)$ and increases with flow depth and water surface slope while the critical shear 
$4 \quad \tau_{c r}=\theta_{c r}\left(\rho_{s}-\rho\right) g D$

$11 v_{c r}=\left(\theta_{c r} G R_{h}{ }^{1 / 3} D\right)^{1 / 2} / n$

$\tau_{b}=\rho g R_{h} S$

$v_{c r}=21 R_{h}{ }^{1 / 6} D^{1 / 3}\left(\theta_{c r} G\right)^{1 / 2}$

$v h=v_{c r}(h+e)$

stress $\tau_{c r}$ is defined in a dimensionless form (Shields et al., 1936) and increases with particle size and bed roughness. They are defined as

where $g$ is acceleration due to gravity (assumed to be $9.8 \mathrm{~ms}^{-2}$ ), $R_{h}$ hydraulic radius, $S$ water surface slope $\left(\mathrm{mm}^{-1}\right), \rho$ water density (assumed to be $1000 \mathrm{kgm}^{-3}$ ), $\rho_{s}$ the sediment density (assumed to be $\left.2650 \mathrm{kgm}^{-3}\right), \theta_{c r}$ the dimensionless shear stress, and $D$ a characteristic grain size (m). Equation (4) represents the moment at which sediment movement begins. Equation (3) was converted in terms of velocity $v$ using the Manning equation $\left(v=\frac{1}{n} R_{h}{ }^{2 / 3} S^{1 / 2}\right)$. Combining the two equations and rewriting the terms, Equation (4) was converted into critical velocity $v_{c r}$, defined as

where $G=\frac{\left(\rho_{s}-\rho\right)}{\rho}$ is the dimensionless submerged specific gravity of the sediment, and $n$ the Manning's $n$ which is estimated by the Strickler equation $\left(n=D^{1 / 6} / 21\right)$ (Strickler, 1923). Rewriting the Manning's $n$ and Equation (5) became

Given a 1D channel with steady and uniform flow, at each cross-section, the relationship between velocity and critical velocity is defined as

where $e$ is the erosion depth $(\mathrm{m})$, and $h$ the water depth (m). Re-arranging the equation, the following equation can be used to calculate the maximum possible bed elevation change, defined as

$e=\left\{\begin{array}{cl}h\left(\frac{v}{v_{c r}}-1\right) & \text { if } v>v_{c r} \\ 0 & \text { if } v \leq v_{c r}\end{array}\right.$

This equation only accounts for the erosion caused by flow at the time that maximum velocity occurred, and makes a couple of assumptions: 1) there were no sediment transported and deposited from upstream; 2) there were no lateral erosion (bank failure) during the flood event; 3) consequences that caused by deposition within the channel such as avulsion, increased lateral erosion, channel instability were neglected; 4) the channel was in rectangular shape along the long profile; and 5) local features such as presence of bedrock and bridges were ignored. In other words, the paper only focusses on the scouring effect of the flood event during the peak caused by the changes in mean bed elevation, before any sediment could deposit downstream as the flood proceeded. Similar with other applications in sediment transport formulae (Gomez and Church, 1989), one calculation is undertaken for each cross-section with the mean depth being input into the equation and such a simple approach may reduce the capability of the equation. The equation is also affected the different sources of error arising from the propagation of error in the measured variables (e.g. McLean et al., 1999) and the spatial variability of bed shear stress (Wilcock, 1996). Moreover, the uncertainty 
involved in the equation is evident in the fact that the values of the dimensionless critical shear stress differ from a variety of roughly a factor of two (Buffington and Montgomery, 1997). Additionally, the equation is sensitive to grain size distribution due to patch dynamics or topographic variability across the channel. Regardless of well-documented limitations in using such formulae approach (Gomez and Church, 1989), sediment transport formulae continue to be widely used and reasonably accepted in geomorphological studies. It is acknowledged that the accuracies of the formulae approach could be improved by building an empirical relationship between transport rate and flow discharge from field measurements (Wilcock, 2001), but effort required to determine this input can be very large, becoming impractical as it involves knowledge of the bed grain size and topography throughout the reach. A balance must then be found between the overall ease of the implementation of the approach and the complexity involved in the equation.

The dimensionless critical shear stress $\theta_{c r}$ and grain size $D$ were believed to be the main source of uncertainty in the equation and thereby considered in this study. The range of values of $\theta_{c r} 0.03$ to 0.06, which cover different flow conditions (Reynolds numbers ranging from $\approx 10$ to $\geq 400$ ), previously reported in the literature (Graf, 1971) were adopted here. Regarding $D$, the simplest and most common approximation was to treat the bed material as a single size fraction (e.g. the median $D_{50}$ ) (Wilcock, 2001). Based on the surveyed grain size data which were sampled at four locations (Isel, Cockermouth, Papcastle, and Great Broughton) along the River Derwent (see Figure 1), the grain size distribution was computed at each site using the Wolman method (Wolman, 1954), whereby grains are blindly selected from the channel every few walks in a rough grid pattern. The Wolman method uses the percentile system to characterise the grain size variability and errors involved in estimating the percentiles using this methods are mainly because of the influence of fluctuations in sampling (Green, 2003). However, assuming that the grain size distribution is lognormal, the precision reduces with distance from the median percentile, $D_{50}$, and only decreases noticeably beyond the 5th and 95th percentiles (Inman, 1952). The 5th (0.048) and 95th (0.082) percentiles were reasonably to be used to represent the entire bed size distribution, while remaining simple enough to permit a practical integral description of the sediment. 300 parameter sets for $\theta_{c r}$ and $D$ were randomly sampled and generated from the range specified accordingly. Despite the rectangular channel assumption, it is expected that the model would perform equally well in terms of optimum RMSE as compared with model with channels of higher complexity (Fewtrell et al., 2011). The results of Fewtrell et al. (2011) also suggested that in order to obtain a good prediction of maximum water levels, it is essential to configure a channel approximation that maintains an estimate of bank-full capacity that is consistent with field observations, as was the case in this study.

The velocities in Equation (7) and critical velocities in Equation (5.1) were determined by running a steady state flow simulation of LISFLOOD-FP. 300 bed elevation scenario cases were then generated by Equation (7) for each behavioural friction parameter set. The 5th and 95th percentiles were extracted to save computational cost and used as inputs in LISFLOOD-FP for re-evaluation of model performance. The two percentile cases represented two extreme scenarios in which the 5th percentile portrayed the least amount of possible erosion while the 95th described the greatest. The same procedure applied and the probabilistic map was again generated for comparison.

In addition, the simulated bed elevation changes were compared with the 93 pairs of observed data points where both pre- and post-flood surveys were taken. The aim of the comparison was to provide 
1 a general idea of how well the hypothetical erosion changes reflected the observed spatial 2 geomorphic changes. The 2010 surveyed cross-section data, in which ten of them had to be modified 3 to account for sediment management undertaken by riparian owners in the intervening period 4 following the flood, were assumed to reflect the nearest river geometry after the 2009 flood event 5 because: 1) comparison between ground based photographs taken immediately after the flood with those taken during the surveys showed no obvious evidence of bar or bank changes in reaches without major sediment management; and, 2) the morphological changes resulting from the 8 November 2009 flood were clearly far greater than any subsequent re-sculpting, or any channel bank migration since the first accurate surveys of the bank line undertaken by the Ordnance Survey in 1867. The data were then used to compute the observed changes in bed elevation for comparison.

\section{Results}

\subsection{Modification of river bed elevations}

Because of the inability of LISFLOOD-FP to dynamically change the channel geometry during simulations, Equation (7) was used to account for the erosion processes during the flood peak and to statically adjust the channel geometry at the start of the simulation. Figure 5a illustrates the hypothetical changes of river bed elevations along River Derwent from downstream. The two dash lines represent the 5th (black) and 95th (grey) percentile calculated erosion depth. Figure 5b displays the 5th percentile bed elevation scenario on subsection of the domain covering the downstream area near Camerton while Figure 5c and 5d show the 95th percentile scenario on subsections of the domain covering area near Great Broughton and the vicinity of Cockermouth and Papacastle respectively. White represents areas of channel where there has been no erosion, and increasing erosion depths $(\mathrm{m})$ are represented by an increase in saturation of red. The 95th percentile scenario displays discontinuous erosion along the reach with little or almost no scouring for the last $5 \mathrm{~km}$ measuring from downstream. Both scenarios showed three major erosion zones: (1) between BNG 311572E 530696N and BNG 311295E 531137N where Cockermouth and Papcastle lie (Figure 5d); (2) at BNG 307774E 531170N near Great Broughton (Figure 5c); and (3) downstream near Camerton at BNG 303832E 530554N and BNG 303623E 530044N (Figure 5b). Yet, care should be taken when looking at the erosion depth at the tight bend in Papcastle as the river floor and width are confined by bedrock, in which the presence of bedrock was not represented in the model. The real values of vertical changes are likely to have been lower than modelled. Local erosion was also predicted to occur at BNG 309795E 530900N and BNG 308295E 530900N respectively due to the presence of two bridges. The bridge structure was not represented explicitly in the model but its effect was simulated by a reduction in channel cross-sectional area at cross-sections co-incident with the bridge resulting in an increase in velocities and subsequent erosion.

The modification of river bed elevations based on Equation (7) was further compared with the 93 pairs of observed data points where both pre- and post-flood surveys were taken. The black dots in Figure 6 show the net differences in observed data points between pre- and post- surveys along the River Derwent from downstream and the envelopes indicate the 5th and 95th percentiles of simulated erosion depth at the observed locations. Negative values mean net erosion and positives net deposition. Referring to the locations where erosion was seen to be the dominant process (between $23.5 \mathrm{~km}$ and $31.3 \mathrm{~km}$ ), the observed bed elevation changes ranged from $-0.06 \mathrm{~m}$ to $-0.84 \mathrm{~m}$ while the 5 th and 95th percentile envelope covered similar ranges (from $-0.02 \mathrm{~m}$ to $-0.75 \mathrm{~m}$ ). Estimated by a 
wide range of percentile envelopes by Equation (7), two locations between $14.8 \mathrm{~km}$ and $17.4 \mathrm{~km}$ and between $2.9 \mathrm{~km}$ and $4.9 \mathrm{~km}$ matched the areas where dynamic geomorphic processes, both erosion and deposition, were observed. The observed bed elevation changes ranged from $-0.54 \mathrm{~m}$ to $+1.00 \mathrm{~m}$ and from $-1.45 \mathrm{~m}$ to $+1.16 \mathrm{~m}$ respectively. Even though the wide range of percentile envelopes provided unrealistic erosion depths (especially between $2.9 \mathrm{~km}$ and $4.9 \mathrm{~km}$ where the 95 th percentile erosion depth could be up to $2.9 \mathrm{~m}$ ), the envelopes do indicate the potential erosive power of the flood at these locations and reveal the areas where dynamic changes could potentially occur.

\subsection{Model sensitivity to parameter roughness values}

After identifying the possible ranges of erosion process during the flood event, the 5th and 95th percentile bed elevation scenarios were then used as inputs in LISFLOOD-FP for re-evaluation of model performance. Figure 6 present the sensitivity of the RMSE between the 300 simulated and observed water levels obtained from the three datasets before and after applying the bed elevation changes using Equation (1). It is immediately noticeable that the model showed no real sensitivity to channel friction, only floodplain friction (Figure $7 \mathrm{left}$ ) for all three datasets. This suggests that the channel friction had little effect on flow conveyance as the floodplain and river channel acted as a single channel unit during the flood event. Even taking the river bed channel changes into consideration, the sensitivity remained similar (Figure 7 middle \& right). However, differences between the parameter spaces were still witnessed. There were noticeable changes in the region for the floodplain optimum. In general, the region for the floodplain optimum for all scenarios moved gradually to a lower floodplain friction value after the flood peak, but a slightly higher region for the peak flood wrack marks dataset and the time of aerial photography in the case of 95th percentile bed elevation scenario.

To further examine the changes in parameter spaces, the optimal friction parameter sets and their RMSEs for each scenario and each dataset are shown in Table 2. Generally, the RMSEs were the lowest for all scenarios at peak flood (wrack marks) and gradually increased when the flood receded (aerial photos and TERRASAR-X image). Applying the bed elevation changes did not improve the RMSE for both 5th and 95th percentile scenarios. The parameter sets of channel and floodplain friction for the peak flood wrack marks dataset and the time of aerial photography varied considerably. Specifically, the value of optimal floodplain friction decreased on the falling limb of the event while that of optimal channel friction appeared to have an increasing trend despite its poor sensitivity. Conversely, the optimal parameter set $\left(n_{c h}: 0.047 ; n_{f p}: 0.020\right)$ for the TERRASAR-X image remained the same for all scenarios. All this suggests that the complexity of channel geometry and long-profile variability is noticeable during and shortly after the flood peak but becomes negligible when the flood further recedes. Given the significant geomorphological change in the river channel and deposition of sediments on the floodplain, the uncertainty in bed elevation changes during this extreme flood event is evident, although the effect of this uncertainty is not dominant compared to other uncertainties. This is perhaps more likely (or largely) to be due to boundary condition uncertainty than any physical change in surface roughness such as through scouring of river beds.

\subsection{Effects of bed elevation changes on prediction of flood depths}


The similar behaviour of the RMSE performance measure and parameter spaces, despite differences in bed elevation scenarios, suggests the modifications due to bed elevation changes are not remarkable in the global friction sensitivity. However, the local dynamics of in-channel and floodplain flows, flood depth and extent may still be affected by the changes in channel geometry and long-profile variability both temporally and spatially. To investigate the influence of bed elevation changes on flood dynamics, the 50th percentile, standard deviation (SD) and coefficient of variation $(\mathrm{CV})$ of inundation depth at the flood peak were computed for three scenarios. Only flooded cells were included in the calculations in order to prevent non-flood cells from skewing the results, as cells which were not flooded in some simulations would have decreased both SD and CV. The 50th percentile inundation depth at the flood peak of the no change scenario is shown in Figure $8 \mathrm{a}$ and two subsections of the domain (Camerton in Figure 8b and Cockermouth and Papcastle in Figure 8c) are zoomed in as areas of interest for better illustration of variability (This also applies to Figure 9). The inundation depth ranged from $0.11 \mathrm{~m}$ at the edge of the floodplain to $5.76 \mathrm{~m}$ in the channel. However, the variations in SD were very different from the inundation depth pattern in which the channel and the surrounding floodplain both had the same variations (Figure 10a(ii)). When mean depth was taken into account using $\mathrm{CV}$, it was the shallowest areas, especially at the edge of the flood, which exhibited the greatest variation in depth (Figure 11a(ii)). The no change scenario was compared with the 5th and 95th percentile bed change scenarios and the differences in inundation depth are shown in Figures $9 \mathrm{a}(\mathrm{i})$ and $9 \mathrm{~b}(\mathrm{i})$ respectively. Increase in mean depth is indicated as green, decrease as red, and no change in white. Overall, the 5th percentile change scenario did not produce much change in the inundation depth of the whole reach, except for the areas (BNG 303800E 530764N) where erosion took place (See Figure 9a(ii)). For instance, the maximum decrease in floodplain water depth was $0.103 \mathrm{~m}$, accompanied with an increase in channel water depth of $0.469 \mathrm{~m}$ at BNG 303935E 530690N. This implies that the effects are localised and do not propagate through the whole model in this case. The result of the 95th percentile change scenario showed a strong association of increase in channel water depth with decrease in its surrounding floodplain water depth (Figure 9b(ii) \& 9b(iii)). The effects in this case, however, propagate downstream as both channel and floodplain water depth increased in the areas after the sections where channels were modified (Figure 9b(i)). This could be due to the fact that where more erosion took place in the channel it led to an increase in channel capacity, which resulted in a delay in time and a shift in location of overbank flow to the floodplain when the flood wave progressed downstream. The variations in SD and CV in the 5th percentile change scenario were similar to that of the no change scenario, excluding an average increase of $0.015 \mathrm{~m}$ and $0.063 \%$ at BNG 303935E $530690 \mathrm{~N}$ (Figure 10b(i) \& 11b(i)). The 95th percentile change scenario had a general decrease in variations in both SD and CV, except for the areas at BNG 303935E 530690N and BNG 311630E $531175 \mathrm{~N}$ where the SD $(0.053 \mathrm{~m}$ and $0.076 \mathrm{~m})$ and $\mathrm{CVs}(0.306 \%$ and $0.248 \%)$ remained high (Figure $10 \mathrm{c}(\mathrm{ii}) \& 11 \mathrm{c}(\mathrm{ii}))$.

Regarding the temporal change of flood inundation area (Figure 12 left) all three scenarios followed the same pattern that the total inundation area increased to a maximum of $6.44 \mathrm{~km}^{2}$ at 77 hours and gradually decreased after reaching the peak. The 5th and 95th percentile bed elevation scenarios simulated smaller flood inundation areas of $6.44 \mathrm{~km}^{2}$ and $6.39 \mathrm{~km}^{2}$ at the later times of 77.25 hours and 78.25hours respectively. Maximum SD occurred 19.5hours and 21.25hours after the time of maximum flood inundation extent in no change and 5th percentile scenarios while that of 95th 
1 percentile scenario came shortly (9.75hours) after the time of maximum flood area. Although the SD

2 in area decreased as the flood moved downstream, the CVs continued to rise to a maximum of $1.50 \%$, $3 \quad 1.50 \%$, and $0.43 \%$ and tended to stabilise as the flood wave receded. These figures suggested that the 4 variation increased through time. However, with the consideration of bed elevation changes, the 5 variations were smaller throughout the simulation even though all scenarios produced similar 6 temporal patterns in total inundation area and time of maximum flood extent.

7 On the other hand, a different trend in SD and CV was observed in the mean channel and floodplain 8 depth of flooding (Figure 12 middle \& right). The greatest variation occurred during the rising limb 9 of the hydrograph, before falling back to a relatively low level. This higher variation in depth during 10 the rising limb than falling limb was expected because this was when flood inundation commenced. 11 However, the variation was restricted to a shorter period of time as flood inundation occurred at a faster rate than flood recession. The maximum SDs of the mean floodplain water depth in three scenarios $(0.0370 \mathrm{~m}, 0.037 \mathrm{~m}$, and $0.009 \mathrm{~m})$ were smaller than that of the mean channel water depth $(0.053 \mathrm{~m}, 0.0543 \mathrm{~m}$, and $0.0135 \mathrm{~m})$ (Figures 12 middle $\mathrm{b} \& 12$ right $\mathrm{b})$ but the maximum CVs of the former were double $(3.172 \%, 3.192 \%$, and $0.765 \%)$ than that of the latter $(1.572 \%, 1.603 \%$, and $0.383 \%$ ) (Figures 12 middle c \& 12 right c). This meant that the variations in mean floodplain water depth in each scenario were larger than that of the mean channel water depth.

\subsection{Effects of bed elevation changes on flood inundation mapping}

Deriving flood inundation maps is important for subsequent decision making for local planning or insurance industry. Accordingly, the effect of bed elevation changes on the mapping of flood inundation was assessed. Based on the RMSE analysis and Equation (2), 31 parameter sets out of 300 were classified as behavioural in the no change bed elevation scenario and were used to generate the probabilistic flood inundation maps at the three observed time intervals. The same procedure was applied to the 5th and 95th percentile scenarios in which 31 and 10 parameter sets were used. The model simulated water depths were converted into a discrete binary format. Adopting the approach in previous studies (e.g. Aronica et al., 2002), only cells with simulated water depths greater than $0.1 \mathrm{~m}$ were assumed to be inundated so as to reflect uncertainties in the exact shoreline location, e.g. caused by emergent vegetation. Figure 13 provides subsections from flood inundation probability maps for the time of maximum flood extent. Generally speaking, the flood margins along the whole reach had a high degree of certainty in flood extent at all three time intervals (refer to Figure 13 top for illustration). This could be due to the fact that it was a valley-fill flood event in which the flood margins were constrained by the both side of the valley, resulting in a highly certain flood boundary. Not surprisingly, the flood margins were more or less as certain as before even taking the bed elevation change scenarios into consideration (Figure 13 bottom). The flood extent of the bed change scenario produced a similar pattern and area with that of the no change scenario despite an increase of channel volume following erosion.

\section{Discussion}

38 In this study, the effect of bed elevation changes on flood dynamics was explored using a simplified 1D-2D hydraulic model, LISFLOOD-FP, within an uncertainty analysis framework applied to modelling of the November 2009 flooding in Cockermouth, North West England. The 5th and 95th 
percentiles bed elevation change scenarios were extracted to represent the range of possible erosion that were derived from a simple velocity based model of critical entrainment. There were numerous sources of uncertainty stemming from morphodynamic processes and from assumptions made that undermined the capability of Equation (7). Since erosion goes with deposition most of the time, on one hand these two effects partially offset one another, on the other channel instability due to braiding caused by deposition can further enhance erosion. More often the effects of deposition are far greater on channel behaviour and thus hydraulics than erosion. Neglecting deposition may result in an overestimation of erosion depths, especially in locations where dynamic geomorphic processes occurred. The model did not incorporate deposition changes, is therefore acknowledged to be a major limitation. However, the model did simulate the range of erosional channel adjustments which are typical of supply limited reaches of river networks. Although no rigorous statistical comparison between observed and estimated erosion depths could be made, the bed elevation modifications generated by Equation (7) reflected a good approximation of realistic spatial erosion pattern when compared with the observed erosion data points. 62 out of 93 pairs of observed data points were recorded as net erosion. Among them there were 23 data points fall within the 5 th and 95 th percentile envelopes. In other words, $37.1 \%$ was estimated within the bed change scenarios. Given the numerous factors that can cause erosion within the channel, the equation that is driven by water depth and indirectly grain size through critical velocity could still be able to capture areas of significant erosional channel changes. The approach was, therefore, good enough for an initial assessment of the erosional impact on flood modelling.

When evaluating the model performance, the three scenarios (no change, 5th and 95th percentiles) displayed similar friction sensitivity for channel and floodplain Manning's $n$. The inclusion of bed elevation changes did not improve the performance of behavioural models, however the use of the RMSE global performance measure will average out local errors, and so therefore might not be the best indicator of where the model performance has improved as a result of accounting for the uncertainty in channel morphology. The regions of behavioural friction parameter sets were reasonably different considering that the only thing being changed was erosional changes to the bed elevation. Greater changes in parameter spaces might be seen if it were two different rivers or events. Constrained by the valley sides and due to the fact that the entire valley floor acted as a single channel unit to convey the flood, the edge of the floodplain along the whole reach had a high degree of certainty in flood extent even though changes in bed elevation were considered. The flood inundation extent was thus not a sensitive measure in this case. It may be argued that larger effect of erosion on flood extent might be seen for smaller flood events as the channel capacity becomes more important when the majority of flow is still held within the channel. However, for this reach these events did no create significant morphological changes, as shown by the evidence that cross-section surveys in the post 2005 flood in the reach through Cockermouth showed minor changes in bed elevation and localised changes in bank outline when compared to those taken in 1998. In addition, since the change in flood extent is dependent on the size of the flood event due to topographic gradient, evaluation of model performance should be achieved using comparison of water surface elevations not spatial patterns of the flood (Stephens et al., In press).

Referring to the changes in water depths within the inundation area, the uncertainty in the simulated mean depth of flooding throughout the flood event, however, had an average increase of $0.68 \%$ to 
$14.31 \%$ in 5th and 95th percentile bed change scenarios. The effects of uncertainty in bed elevation changes on flood dynamics were also observed both through time and with distance downstream.

3 Temporally speaking, variations in mean channel and floodplain depth of flooding were greater but 4 shorter during rising limb than falling limb. Despite its negligible change in water depth, the 5 variations in mean floodplain water depth were larger than that of the mean channel water depth. 6 Referring to the spatial patterns, local bed elevation changes became the principal control over where flood water initially flowed. Regions furthest away from the channel generally tended to have a higher degree of variability, areas where calculated erosion took place, however, also caused the near-channel floodplain to have greater variations in the time of initial flooding. Perhaps it would be interesting to look at the probability of localised channel breaching and its impact would have on floodplain inundation, but this is outside the scope of the data that is available as it would need to include some prior knowledge of the condition of the banks to get the probabilities of breaching remotely correct.

\section{Conclusion}

Overall, the inclusion of bed elevation changes appeared to alter the flood dynamics locally, and although this effect was noticeable in the global friction sensitivity, it was not significant for the flood inundation mapping. Given that the November 2009 flooding in Cockermouth was an extreme flood event with significant geomorphological changes, the effects of uncertainty in the bed elevation changes on flood dynamics were noticeable but relatively small. It is more likely that the boundary conditions or errors in observed data could have a larger impact on the model performance as well as on acceptable effective roughness values. For instance, an analysis of rating curve uncertainties could lead to an uncertainty in the input of $18-25 \%$ at peak discharge (Pappenberger et al., 2006). It is highly possible that the rating curve uncertainties arising from the extrapolation of the rating curve and errors in estimating the peak discharge are even greater for this flood event. Therefore, this study has shown that hydraulic models might not need to account for within event morphodynamic changes as these can have a negligible impact compared to other uncertainties. However, the conclusions of this study are limited in that they only represent simplified and erosional cross-section changes and did not account for the significant changes in cross-section (bank erosion) and deposition. Similarly, in catchments with much larger sediment supply, changes may well include channel blocking and avulsion, neither of which were included within this model. While we conclude that morphodynamic change needs to happen over a series of events to become large enough to change the hydrodynamics of floods in the UK, given the assumptions in this study future work should be undertaken to concentrate on two areas: 1) the effects of the full range of morphological adjustments and, 2) the agglomerative changes in channel morphology resulting from flood sequences and how the uncertainties of each flood event propagate to the next; the latter becoming more significant with increased flood frequency.

\section{ACKNOWLEDGMENTS}

Jefferson Wong was funded by University of Bristol Postgraduate Scholarship. The authors would 


\section{Reference}

Apel H, Aronica GT, Kreibich H, Thieken AH. 2009. Flood risk analyses-how detailed do we need to be? Nat Hazards, 49: 79-98. DOI: DOI 10.1007/s11069-008-9277-8.

Aronica G, Bates PD, Horritt MS. 2002. Assessing the uncertainty in distributed model predictions using observed binary pattern information within GLUE. Hydrol Process, 16: 2001-2016. DOI: Doi 10.1002/Hyp.398.

Aronica G, Hankin B, Beven K. 1998. Uncertainty and equifinality in calibrating distributed roughness coefficients in a flood propagation model with limited data. Adv Water Resour, 22: 349-365. DOI: Doi 10.1016/S0309-1708(98)00017-7.

Bates PD, De Roo APJ. 2000. A simple raster-based model for flood inundation simulation. J Hydrol, 236: 54-77. DOI: Doi 10.1016/S0022-1694(00)00278-X.

Bates PD, Horritt MS, Aronica G, Beven K. 2004. Bayesian updating of flood inundation likelihoods conditioned on flood extent data. Hydrol Process, 18: 3347-3370. DOI: Doi 10.1002/Hyp.1499.

Bates PD, Horritt MS, Fewtrell TJ. 2010. A simple inertial formulation of the shallow water equations for efficient two-dimensional flood inundation modelling. J Hydrol, 387: 33-45. DOI: 10.1016/j.jhydrol.2010.03.027.

Bates PD, Horritt MS, Hunter NM, Mason D, Cobby D. 2005. Numerical Modelling of Floodplain Flow. In: Computational Fluid Dynamics, John Wiley \& Sons, Ltd, pp: 271-304.

Beven K, Binley A. 1992. The future of distributed models: model calibration and predictive uncertainty. Hydrol. Processes, 6: 279-298.

Beven K, Leedal D, Alcock R, Hunter N, Keef C, Lamb R. 2012. Guidelines for good practice in flood risk mapping: The catchment change network. In: International Interdisciplinary Conference on Predictions for Hydrology, Ecology and Water Resources Management.

Brunner G. 2002. HEC-RAS, River analysis system user's manual, version 3.1: Davis, California. US Army Corps of Engineers Hydrologic Engineering Center, Report CPD-68, variously paginated.

Buffington JM, Montgomery DR. 1997. A systematic analysis of eight decades of incipient motion studies, with special reference to gravel-bedded rivers. Water Resour Res, 33: 1993-2029. DOI: Doi 10.1029/96wr03190.

Chow VT. 1959. Open-channel hydraulics. McGraw Hill, New York.

Cook A, Merwade V. 2009. Effect of topographic data, geometric configuration and modeling approach on flood inundation mapping. J Hydrol, 377: 131-142. DOI: DOI 10.1016/j.jhydrol.2009.08.015.

Di Baldassarre G, Schumann G, Bates PD. 2009. A technique for the calibration of hydraulic models using uncertain satellite observations of flood extent. J Hydrol, 367: 276-282. DOI: http://dx.doi.org/10.1016/j.jhydrol.2009.01.020.

DuBoys M. 1879. Le Rhône et les rivières à lit affouillable. Ann. Ponts Chaussees, 18: 141-148.

Fewtrell TJ, Neal JC, Bates PD, Harrison PJ. 2011. Geometric and structural river channel complexity and the prediction of urban inundation. Hydrol Process, 25: 3173-3186. DOI: Doi 10.1002/Hyp.8035.

Freer J, Beven K, Peters N. 2003. Multivariate seasonal period model rejection within the generalised likelihood uncertainty estimation procedure. In: Calibration of Watershed Models, AGU, pp: 69-87.

Galland JC, Goutal N, Hervouet JM. 1991. Telemac - a New Numerical-Model for Solving Shallow-Water Equations. Adv Water Resour, 14: 138-148. DOI: Doi 10.1016/0309-1708(91)90006-A.

Gomez B, Church M. 1989. An Assessment of Bed-Load Sediment Transport Formulas for Gravel Bed Rivers. Water Resour Res, 25: 1161-1186. DOI: Doi 10.1029/Wr025i006p01161.

Graf WH. 1971. Hydraulics of sediment transport. McGraw-Hill.

Green JC. 2003. The precision of sampling grain-size percentiles using the Wolman method. Earth Surf Proc Land, 28: 979-991. DOI: Doi 10.1002/Esp.513.

Hey RD. 1979. Flow Resistance in Gravel-Bed Rivers. J Hydr Eng Div-Asce, 105: 365-379.

Hunter NM, Bates PD, Neelz S, Pender G, Villanueva I, Wright NG, Liang D, Falconer RA, Lin B, Waller S, Crossley AJ, Mason DC. 2008. Benchmarking 2D hydraulic models for urban flooding. P I Civil EngWat M, 161: 13-30. DOI: DOI 10.1680/wama.2008.161.1.13.

Inman DL. 1952. Measures for describing the size distribution of sediments. Journal of Sedimentary Research, 22: $125-145$.

Kleinhans MG, Ferguson RI, Lane SN, Hardy RJ. 2013. Splitting rivers at their seams: bifurcations and avulsion. Earth Surf Proc Land, 38: 47-61. DOI: Doi 10.1002/Esp.3268. 
Lamb R, Beven K, Myrabo S. 1998. Use of spatially distributed water table observations to constrain uncertainty in a rainfall-runoff model. Adv Water Resour, 22: 305-317. DOI: Doi 10.1016/S03091708(98)00020-7.

Lane SN, Reid SC, Tayefi V, Yu D, Hardy RJ. 2008. Reconceptualising coarse sediment delivery problems in rivers as catchment-scale and diffuse. Geomorphology, 98: 227-249. DOI: DOI 10.1016/j.geomorph.2006.12.028.

Lane SN, Tayefi V, Reid SC, Yu D, Hardy RJ. 2007. Interactions between sediment delivery, channel change, climate change and flood risk in a temperate upland environment. Earth Surf Proc Land, 32: 429-446. DOI: Doi 10.1002/Esp.1404.

Mason DC, Bates PD, Amico JTD. 2009. Calibration of uncertain flood inundation models using remotely sensed water levels. J Hydrol, 368: 224-236. DOI: DOI 10.1016/j.jhydrol.2009.02.034.

McLean DG, Church M, Tassone B. 1999. Sediment transport along lower Fraser River - 1. Measurements and hydraulic computations. Water Resour Res, 35: 2533-2548.

Merwade V, Cook A, Coonrod J. 2008. GIS techniques for creating river terrain models for hydrodynamic modeling and flood inundation mapping. Environ Modell Softw, 23: 1300-1311. DOI: DOI 10.1016/j.envsoft.2008.03.005.

Merwade V, Olivera F, Arabi M, Edleman S. 2008. Uncertainty in Flood Inundation Mapping: Current Issues and Future Directions. Journal of Hydrologic Engineering, 13: 608-620. DOI: doi:10.1061/(ASCE)1084-0699(2008)13:7(608).

Miller JD, Kjeldsen TR, Hannaford J, Morris DG. 2013. A hydrological assessment of the November 2009 floods in Cumbria, UK. Hydrology Research, 44: 180-197. DOI: Doi 10.2166/Nh.2012.076.

Neuhold C, Stanzel P, Nachtnebel H. 2009. Incorporating river morphological changes to flood risk assessment: uncertainties, methodology and application. Nat Hazard Earth Sys, 9: 789-799.

Pappenberger F, Beven K, Horritt M, Blazkova S. 2005. Uncertainty in the calibration of effective roughness parameters in HEC-RAS using inundation and downstream level observations. J Hydrol, 302: 46-69. DOI: DOI 10.1016/j.jhydrol.2004.06.036.

Pappenberger F, Frodsham K, Beven K, Romanowicz R, Matgen P. 2007. Fuzzy set approach to calibrating distributed flood inundation models using remote sensing observations. Hydrol Earth Syst Sc, 11: 739-752.

Pappenberger F, Matgen P, Beven KJ, Henry JB, Pfister L, Fraipont de P. 2006. Influence of uncertain boundary conditions and model structure on flood inundation predictions. Adv Water Resour, 29: 1430-1449. DOI: DOI 10.1016/j.advwatres.2005.11.012.

Raven EK, Lane SN, Ferguson RI, Bracken LJ. 2009. The spatial and temporal patterns of aggradation in a temperate, upland, gravel-bed river. Earth Surf Proc Land, 34: 1181-1197. DOI: Doi 10.1002/Esp.1783.

Romanowicz R, Beven K. 2003. Estimation of flood inundation probabilities as conditioned on event inundation maps. Water Resour. Res., 39: 1073. DOI: 10.1029/2001 wr001056.

Sear DA, Newson MD, Thorne CR. 2010. Guidebook of applied fluvial geomorphology. Thomas Telford.

Shields A, Ott W, Van Uchelen J. 1936. Application of similarity principles and turbulence research to bedload movement.

Stephens EM, Bates PD. In revision. Assessing the reliability of probabilistic flood inundation model predictions of the November 2009 flood in Cockermouth, UK. J Hydrol.

Stephens EM, Bates PD, Freer JE, Mason DC. 2012. The impact of uncertainty in satellite data on the assessment of flood inundation models. J Hydrol, 414: 162-173. DOI: DOI 10.1016/j.jhydrol.2011.10.040.

Stephens EM, Schumann G, Bates PD. In press. Problems with Binary Pattern Measures for Flood Inundation Extent. Hydrol Process.

Stover SC, Montgomery DR. 2001. Channel change and flooding, Skokomish River, Washington. J Hydrol, 243: 272-286. DOI: Doi 10.1016/S0022-1694(00)00421-2.

Strickler A. 1923. Beiträge zur Frage der Geschwindigkeitsformel und der Rauhigkeitszahlen für Ströme, Kanäle und geschlossene Leitungen. Société du Bulletin technique de la Suisse romande.

Trigg MA, Wilson MD, Bates PD, Horritt MS, Alsdorf DE, Forsberg BR, Vega MC. 2009. Amazon flood wave hydraulics. J Hydrol, 374: 92-105. DOI: DOI 10.1016/j.jhydrol.2009.06.004.

Wagener T, Lees MJ, Wheater HS. 2002. A toolkit for the development and application of parsimonious hydrological models. Mathematical models of large watershed hydrology, 1: 87-136. 
Werner M, Blazkova S, Petr J. 2005. Spatially distributed observations in constraining inundation modelling uncertainties. Hydrol Process, 19: 3081-3096. DOI: Doi 10.1002/Hyp.5833.

Werner M, Hunter NM, Bates PD. 2005. Identifiability of distributed floodplain roughness values in flood extent estimation. J Hydrol, 314: 139-157. DOI: DOI 10.1016/j.jhydrol.2005.03.012.

Wheaton JM, Brasington J, Darby SE, Sear DA. 2010. Accounting for uncertainty in DEMs from repeat topographic surveys: improved sediment budgets. Earth Surf Proc Land, 35: 136-156. DOI: Doi 10.1002/Esp.1886.

Wilcock PR. 1996. Estimating local bed shear stress from velocity observations. Water Resour Res, 32: 33613366. DOI: Doi 10.1029/96wr02277.

Wilcock PR. 2001. Toward a practical method for estimating sediment-transport rates in gravel-bed rivers. Earth Surf Proc Land, 26: 1395-1408. DOI: Doi 10.1002/Esp.301.

Wilson MD, Atkinson PM. 2005. Prediction uncertainty in floodplain elevation and its effect on flood inundation modelling. GeoDynamics: 185-202.

Wolman MG. 1954. A method of sampling coarse river-bed material. Transactions, American Geophysical Union, 35: 951-956. 


\section{Page 19 of 19}

Table 1 Summary statistics of cross-section survey

\begin{tabular}{|l|l|l|}
\hline & \multicolumn{1}{|c|}{ Pre-flood survey } & \multicolumn{1}{c|}{ Post-flood survey } \\
\hline Date of survey & 1998 by EA & $\begin{array}{l}\text { December 2009 by EA } \\
\text { May and August 2010 by } \\
\text { this study }\end{array}$ \\
\hline No. of cross-section & 234 & 191 \\
\hline Mean spacing (m) & 124 & 151 \\
\hline Mean point spacing (m) & 1.09 & 3.35 \\
\hline Minimum elevation (m) & 4.20 & 3.03 \\
\hline Maximum elevation (m) & 67.44 & 69.72 \\
\hline
\end{tabular}

2

4 Table 2 Optimal parameter sets of channel and floodplain friction identified using RMSE for three bed elevation scenarios and for three datasets.

\begin{tabular}{|c|c|c|c|c|}
\hline & $\begin{array}{l}\text { Bed Elevation } \\
\text { Scenario }\end{array}$ & $\begin{array}{l}\text { Channel } \\
\text { Friction }\end{array}$ & $\begin{array}{c}\text { Floodplain } \\
\text { Friction }\end{array}$ & $\begin{array}{l}\text { RMSE } \\
(\mathrm{m})\end{array}$ \\
\hline \multirow[t]{3}{*}{ Wrack Marks } & No change & $\begin{array}{c}0.022- \\
0.042 \\
\end{array}$ & 0.044 & 0.2751 \\
\hline & $5 \%$ percentile & 0.067 & 0.045 & 0.2759 \\
\hline & $95 \%$ percentile & $\begin{array}{c}0.067- \\
0.132\end{array}$ & 0.05 & 0.3059 \\
\hline \multirow[t]{3}{*}{ Aerial Photos } & No change & $\begin{array}{c}0.038- \\
0.135\end{array}$ & 0.029 & 0.4187 \\
\hline & $5 \%$ percentile & $\begin{array}{c}0.036- \\
0.061\end{array}$ & 0.028 & 0.4187 \\
\hline & $95 \%$ percentile & $\begin{array}{l}0.05- \\
0.067\end{array}$ & 0.038 & 0.4311 \\
\hline \multirow{3}{*}{$\begin{array}{l}\text { TERRASAR- } \\
\text { X Image }\end{array}$} & No change & 0.047 & 0.020 & 0.6303 \\
\hline & $5 \%$ percentile & 0.047 & 0.020 & 0.6281 \\
\hline & $95 \%$ percentile & 0.047 & 0.020 & 0.6084 \\
\hline
\end{tabular}

